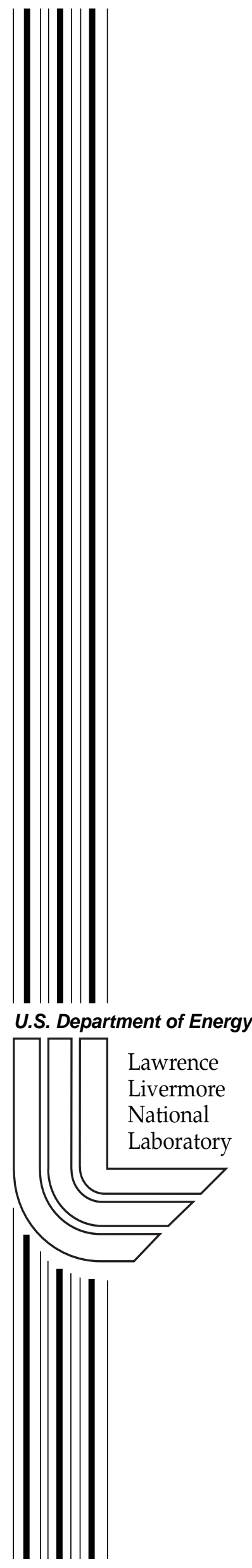

Preprint

UCRL-JC-159559

\title{
Short Range Chemical Ordering in Bulk Metallic Glasses
}

P. A. Sterne, P. Asoka-Kumar, J. H. Hartley, R. H. Howell, T. G. Nieh, K. M. Flores, D. Suh, R. H. Dauskardt

This article was submitted to the Materials Research Society Fall 2000 Meeting, Boston, MA, November 27-December 1, 2000

\section{January 3, 2001}




\section{DISCLAIMER}

This document was prepared as an account of work sponsored by an agency of the United States Government. Neither the United States Government nor the University of California nor any of their employees, makes any warranty, express or implied, or assumes any legal liability or responsibility for the accuracy, completeness, or usefulness of any information, apparatus, product, or process disclosed, or represents that its use would not infringe privately owned rights. Reference herein to any specific commercial product, process, or service by trade name, trademark, manufacturer, or otherwise, does not necessarily constitute or imply its endorsement, recommendation, or favoring by the United States Government or the University of California. The views and opinions of authors expressed herein do not necessarily state or reflect those of the United States Government or the University of California, and shall not be used for advertising or product endorsement purposes.

This is a preprint of a paper intended for publication in a journal or proceedings. Since changes may be made before publication, this preprint is made available with the understanding that it will not be cited or reproduced without the permission of the author.

This work was performed under the auspices of the United States Department of Energy by the University of California, Lawrence Livermore National Laboratory under contract No. W-7405-Eng-48.

This report has been reproduced directly from the best available copy.

Available electronically at http://www.doc.gov/bridge

Available for a processing fee to U.S. Department of Energy

And its contractors in paper from

U.S. Department of Energy

Office of Scientific and Technical Information

P.O. Box 62

Oak Ridge, TN 37831-0062

Telephone: (865) 576-8401

Facsimile: (865) 576-5728

E-mail: reports@adonis.osti.gov

Available for the sale to the public from

U.S. Department of Commerce

National Technical Information Service

5285 Port Royal Road

Springfield, VA 22161

Telephone: (800) 553-6847

Facsimile: (703) 605-6900

E-mail: orders@ntis.fedworld.gov

Online ordering: http://www.ntis.gov/ordering.htm

Or

Lawrence Livermore National Laboratory

Technical Information Department's Digital Library

http://www.llnl.gov/tid/Library.html 


\title{
Short Range Chemical Ordering in Bulk Metallic Glasses
}

\author{
P. A. Sterne ${ }^{1}$, P. Asoka-Kumar ${ }^{1}$, J. H. Hartley ${ }^{1}$, R. H. Howell ${ }^{1}$, T.G. Nieh ${ }^{1}$, K. M. Flores ${ }^{2}$, \\ D. Suh $^{2}$, and R. H. Dauskardt ${ }^{2}$ \\ ${ }^{1}$ Lawrence Livermore National Laboratory, P.O. Box 808, Livermore, CA 94550 \\ ${ }^{2}$ Department of Materials Science and Engineering, Stanford University, Stanford, CA 94305
}

\begin{abstract}
We provide direct experimental evidence for a non-random distribution of atomic constituents in $\mathrm{Zr}$-based multi-component bulk metallic glasses using positron annihilation spectroscopy. The Ti content around the open-volume regions is significantly enhanced at the expense of $\mathrm{Cu}$ and $\mathrm{Ni}$, indicating that $\mathrm{Cu}$ and $\mathrm{Ni}$ occupy most of the volume bounded by their neighboring atoms while $\mathrm{Ti}$ and $\mathrm{Zr}$ are less closely packed and more likely to be associated with open-volume regions. Temperature-dependent measurements indicate the presence of at least two different characteristic sizes for the open volume regions. Measurements on hydrogencharged samples show that the larger open-volume regions can be filled by hydrogen up to a critical density. Beyond this critical density, local atomic-scale open-volume damage is created in the sample to accommodate additional hydrogen. The onset of this local damage in positron annihilation data coincides with the onset of volume expansion in X-ray diffraction data.
\end{abstract}

\section{INTRODUCTION}

A number of zirconium-based multi-component alloys form bulk metallic glasses at relatively slow cooling rates [1,2]. These glasses exhibit a number of interesting physical properties, including large elastic strains to failure, unusual diffusion characteristics, and high tensile strengths [3-5]. Little is known about the detailed atomic arrangement of these metallic glasses, and how any such atomic structure may influence their mechanical properties. The fundamental processes responsible for atomic mobility and rearrangement are different from those for crystalline materials, and may be influenced by defect-like open-volume regions [4].

Positron annihilation spectroscopy (PAS) provides a sensitive probe of open-volume regions and defects in materials [6]. Positrons tend to occupy open-volume regions due to their Coulomb repulsion with the atomic nuclei. Consequently, positrons preferentially annihilate with electrons associated with atoms adjacent to these open-volume regions. Positron lifetimes measure the characteristic size of these regions, and previous work indicates that the metallic glasses studied here have single-component lifetime values that lie between those for the constituent bulk metals and metal vacancies $[7,8]$.

Positron Doppler broadening experiments measure the electron-momentum distribution. The high-momentum part of this distribution results from annihilation with electrons that retain their orbital character in the solid, such as core electrons and atomic-like transition-metal delectrons. The resulting momentum distributions are therefore characteristic of the atom type, and so can be used to determine the chemical species associated with the open-volume regions of 
the metallic glass. The elemental specificity of this technique has been established in recent studies [9-11].

We have used positron annihilation spectroscopy to examine the properties of two different sets of Zr-based multi-component alloys. We find evidence for chemical short-range order in the metallic glass, indicating that the atomic distribution is not entirely random. Temperaturedependent measurements indicate the presence of at least two different characteristic sizes for the open-volume regions. We demonstrate that the larger-volume holes can be filled by hydrogencharging up to a critical amount of hydrogen. Beyond this critical value, additional hydrogen charging creates atomic-scale open-volume damage in the glass. The onset of damage seen in positron annihilation coincides with the onset of volume expansion seen in X-ray diffraction.

\section{EXPERIMENTAL}

Electron momentum measurements were performed using a standard two-detector coincidence setup $[9,11]$. Room temperature measurements were performed using a $3 \mathrm{MeV}$ positron accelerator [12]. The positrons from this beam are deposited in the bulk of the sample, so these measurements are insensitive to near-surface contributions. Temperature-dependent measurements were performed using a ${ }^{22} \mathrm{Na}$ source providing a range of positron energies up to about $1.2 \mathrm{MeV}$.

Two different sets of samples were used in this study. The $\mathrm{Zr}_{52.5} \mathrm{Ti}_{5} \mathrm{Al}_{10} \mathrm{Cu}_{17.9} \mathrm{Ni}_{14.6}$ samples were prepared at Oak Ridge National Laboratory by arc melting in inert gas, followed by drop casting. The $\mathrm{Zr}_{41.25} \mathrm{Ti}_{13.75} \mathrm{Ni}_{10} \mathrm{Cu}_{12.5} \mathrm{Be}_{22.5}$ samples were prepared by EDM. Both sets of samples were approximately $6 \mathrm{~mm}$ thick, sufficient to stop the high-energy positron beam. Hydrogencharging of the $\mathrm{Zr}_{41.25} \mathrm{Ti}_{13.75} \mathrm{Ni}_{10} \mathrm{Cu}_{12.5} \mathrm{Be}_{22.5}$ metallic glasses was performed ex situ using a cathodic charging technique under constant current conditions [13]. Since the highly penetrating $3 \mathrm{MeV}$ positron beam was used for most of this study, no special surface preparations were performed on the samples.

\section{RESULTS AND DISCUSSION}

\section{Chemical Short-Range Order}

Figure 1 shows the electron momentum density for $\mathrm{Zr}_{52.5} \mathrm{Ti}_{5} \mathrm{Al}_{10} \mathrm{Cu}_{17.9} \mathrm{Ni}_{14.6}$. In order to enhance the features, we have plotted the ratio of the momentum density to an arbitrary reference spectrum. The solid line is obtained by combining experimental spectra from well-annealed elemental metal samples of the alloy's components in proportion to the atomic percentage of each element in the metallic glass. The large difference between the solid line and the data for the metallic glass indicates that the positrons do not sample all atomic species in the glass equally. By using the elemental metal spectra as fitting functions, we can determine an effective chemical composition as seen by the positron. The resulting fitting parameters are listed in Table I. The positron sees strong contributions from the $\mathrm{Zr}$ and $\mathrm{Ti}$ atoms, with a large enhancement of the Ti component over that expected on the basis of the atomic composition, and a correspondingly large reduction in the contributions from $\mathrm{Ni}$ and $\mathrm{Cu}$.

The observed deviations from atomic composition are a direct consequence of the positron 


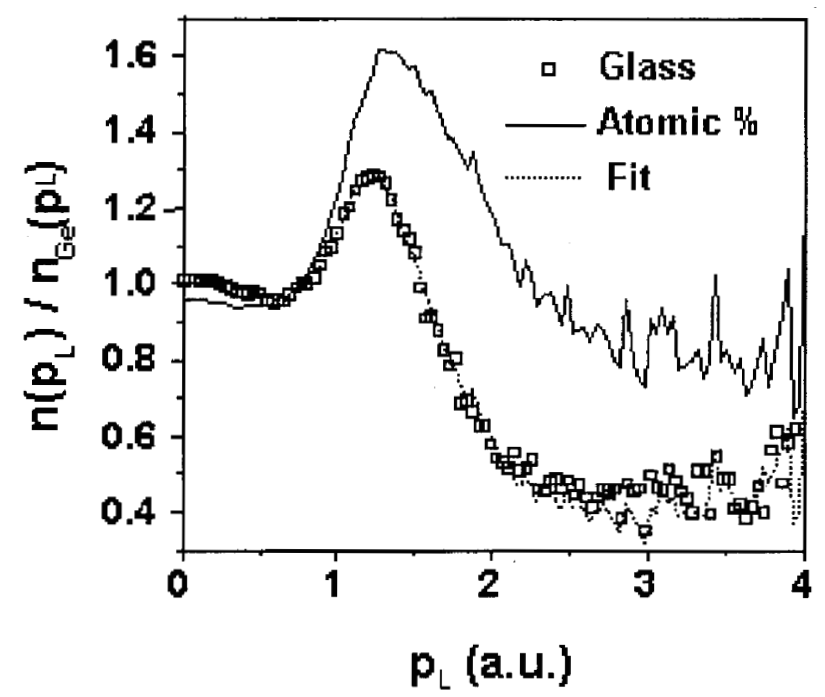

Figure 1. Ratio of electron momentum density $n\left(p_{L}\right)$ for $\mathrm{Zr}_{52.5} \mathrm{Ti}_{5} \mathrm{Al} \mathrm{l}_{10} \mathrm{Cu} \mathrm{u}_{17.9} \mathrm{Ni} i_{14.6}$ to a reference Ge spectrum. The solid line is the expected spectrum based on the atomic percentages of the metallic glass components. The dotted line is a least-squares fit to the experimental data points (squares) using a linear combination of the experimental spectra for well-annealed bulk elemental reference samples. The coefficients in the fit are given in Table 1.

Table I. Composition of constituent elements for $\mathrm{Zr}_{52.5} \mathrm{Ti}_{5} \mathrm{Al}_{10} \mathrm{Cu}_{17.9} \mathrm{Ni}_{14.6}$ as given by positron annihilation measurements. $\mathrm{Ni}$ and $\mathrm{Cu}$ spectra were too similar to be resolved, so they are represented by a single component.

\begin{tabular}{|c|c|c|}
\hline Element & Atomic comp. & Fit \\
\hline $\mathrm{Al}$ & 0.1 & 0.081 \\
\hline $\mathrm{Ti}$ & 0.05 & 0.336 \\
\hline $\mathrm{Ni}+\mathrm{Cu}$ & 0.325 & 0.083 \\
\hline $\mathrm{Zr}$ & 0.525 & 0.503 \\
\hline
\end{tabular}

distribution. Since the positron samples open-volume regions, these differences in positron sensitivity are due to differences in the local atomic coordination around each atomic species, and their affinity for open-volume regions. Our results therefore indicate the existence of shortrange chemical order in the metallic glass: $\mathrm{Ni}$ and $\mathrm{Cu}$ are closely surrounded by their neighboring atoms, resulting in a lower sensitivity to positrons, while $\mathrm{Ti}$ and $\mathrm{Zr}$ are associated with more open-volume regions, consistent with a smaller number of nearest neighbor atoms and a preference for open-volume regions. The given results were taken on an as-received sample. No significant changes were observed after a low temperature $\left(200^{\circ} \mathrm{C}\right)$ anneal [8]. A similar enhancement in the $\mathrm{Ti}$ component and reduction in the $\mathrm{Cu}$ and $\mathrm{Ni}$ components was also observed for the $\mathrm{Zr}_{41.25} \mathrm{Ti}_{13.75} \mathrm{Ni}_{10} \mathrm{Cu}_{12.5} \mathrm{Be}_{22.5}$ metallic glasses.

\section{Temperature Dependence}

It is often helpful to reduce the full electron momentum dataset to facilitate analysis. One commonly used dataset reduction involves computing the low-momentum fraction in the 


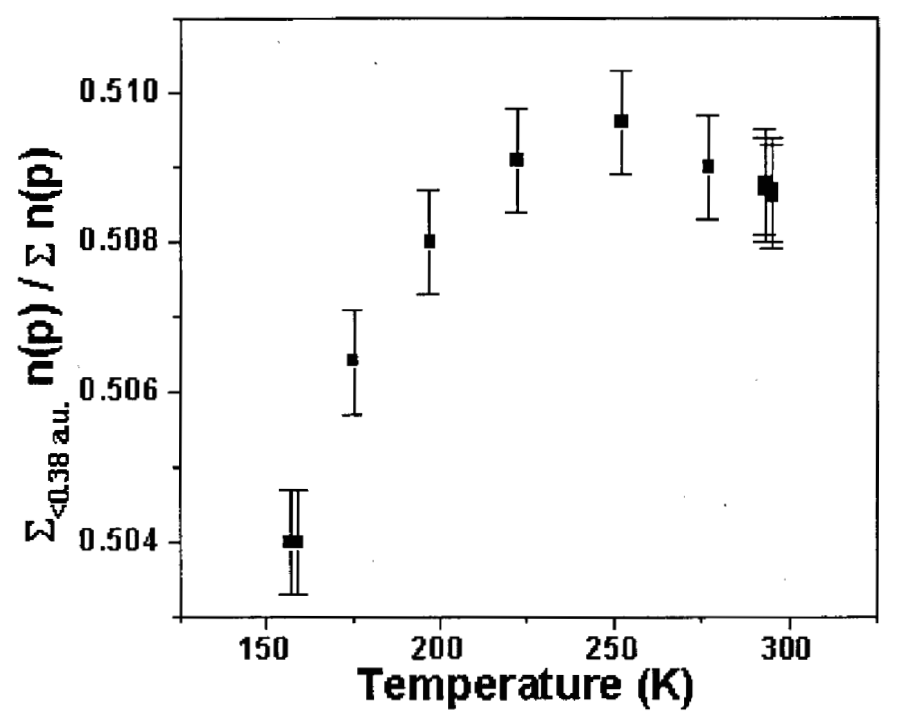

Figure 2. Temperature variation of the low-momentum fraction $(n(p)<0.38)$ of the electron-momentum density, $n(p)$. Larger values correspond to increased annihilation with valence electrons and a corresponding reduction in core annihilation.

spectrum by summing all electron momentum density contributions with momentum less than some cutoff ( 0.38 a.u.), and dividing this by the total integrated spectrum value. This fractional value, often referred to as the S-parameter, gives a measure of the amount of annihilation with valence electrons [6]. Large values for the low-momentum fraction imply mostly annihilation with delocalized low-momentum electrons, suggesting that the positron occupies open-volume regions well removed from the core electrons. Conversely, small values for this component suggest that the positron has significant overlap with core electrons and is therefore in a smaller open-volume region.

Figure 2 shows a plot of the low-momentum component vs. temperature for the metallic glass $\mathrm{Zr}_{41.25} \mathrm{Ti}_{13.75} \mathrm{Ni}_{10} \mathrm{Cu}_{12.5} \mathrm{Be}_{22.5}$. The increase in value of the low-momentum component with increasing temperature suggests a change in the positron environment. At low temperatures, the positron has little thermal energy, so it is confined in a small region of space where it ultimately annihilates. At higher temperatures, the positron has a higher thermal energy, so it diffuses further before annihilating, allowing it to find larger open-volume regions. The increase in lowmomentum fraction therefore indicates the existence of at least two characteristic sizes for the open volume regions in the metallic glass. At low temperatures, the positron remains in the smaller volume regions since it has insufficient thermal energy to escape. At higher temperatures, the positron diffuses out of the smaller-volume regions and is subsequently trapped in slightly larger open-volume regions, with a corresponding increase in the low-momentum component due to the change in overlap with the core and valence electrons.

\section{Hydrogen Charged Samples}

Hydrogen charging increases the hardness of metallic glasses [13]. X-Ray diffraction measurements suggest that hydrogen charging occurs without appreciable volume expansion up 


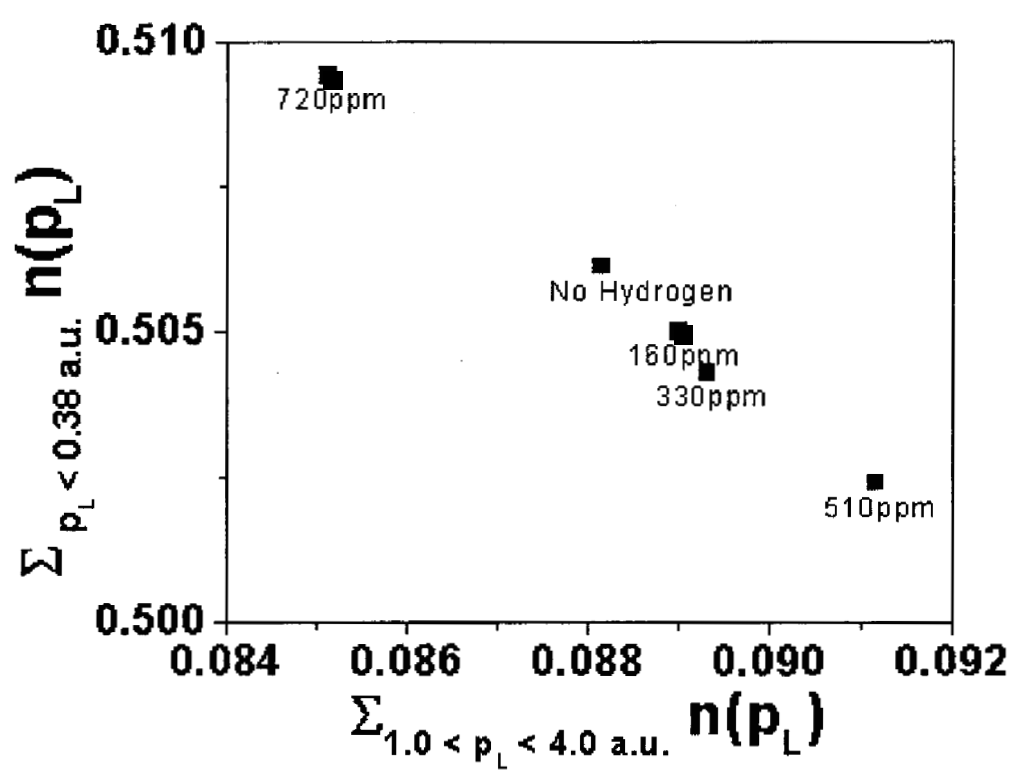

Figure 3. Plot of low momentum fraction vs. high momentum fraction for hydrogen-charged samples. Low momentum fraction $(n(p)<0.38 a$. u.) is largest for open-volume regions that favor annihilation with valence electrons. High momentum fraction (la.u. $<n(p)<4 a . u$.) is largest for smaller volume regions with significant core overlap. Note that hydrogen charging initially moves in the direction of increased core contribution, but reverses to increased open-volume-like valence contribution above $510 \mathrm{ppm}$.

to around 550 appm [14]. This suggests that hydrogen may occupy existing open-volume regions in the metallic glass up to this critical concentration. Figure 3 shows a plot of high momentum fraction vs. low momentum fraction for $\mathrm{Zr}_{41.25} \mathrm{Ti}_{13.75} \mathrm{Ni}_{10} \mathrm{Cu}_{12.5} \mathrm{Be}_{22.5}$ samples with a range of hydrogen charging. The high momentum fraction, often referred to as the $\mathrm{W}$-parameter, is fraction of electron momentum density between 1 and 4 a.u. and is largest when there is a large core-electron contribution to the positron annihilation [6]. The variations in high and low momentum fraction show an increase in the amount of core annihilation and a reduction in valence annihilation with increasing hydrogen charging up to $510 \mathrm{appm}$. This is consistent with the hydrogen occupying the larger open-volume regions, thereby excluding the positrons and forcing them to occupy the smaller open-volume regions. Above $510 \mathrm{appm}$, the trend reverses, and we see a large increase in the low-momentum component and a reduction in the highmomentum component, suggesting that the positron is once again in larger open-volume regions. This coincides with the onset of volume expansion in X-ray diffraction [14], suggesting that the hydrogen has filled all the larger open-volume regions that are immediately accessible, and must therefore create open-volume damage to accommodate more hydrogen.

\section{CONCLUSIONS}

We have used positron annihilation spectroscopy to investigate the open-volume regions in bulk metallic glasses. Electron momentum measurements indicate that the positron does not see the atomic species in proportion to their atomic composition in the alloy. Ti and $\mathrm{Zr}$ are seen much more strongly than the other components, indicating that the other components are more closely coordinated by their neighboring atoms and so less accessible to the positron which 
favors the open-volume regions. Temperature measurements showed a change in the lowmomentum component with temperature, indicating that there are at least two characteristic sizes for the open-volume regions. Thermal trapping into these regions changes with temperature, and favors the larger open-volume regions at higher temperature. Hydrogen doping appears to fill these larger open-volume regions, driving the positron back into the smaller open-volume regions. However once the available holes are filled with hydrogen, further charging creates local atomic-scale damage in the metallic glass, leading once again to positron localization in large open-volume regions. This interpretation is consistent with X-ray diffraction data which shows an onset of volume expansion around 550appm.

\section{ACKNOWLEDGMENTS}

This work was performed under the auspices of the U.S. Department of Energy by University of California Lawrence Livermore National Laboratory under contract No. W-7405Eng-48 and supported by the Department of Energy, Office of Basic Energy Sciences. This work was supported by the Air Force Office of Scientific Research under AFOSR Grant No. F49620-98-1-0260.

\section{REFERENCES}

1. T. Zhang, A. Inoue, and T. Masumoto, Mater. Trans., JIM 32, 1005 (1991).

2. A. Peker and W. L. Johnson, Appl. Phys. Lett. 63, 2342 (1993).

3. W.L. Johnson and A. Peker, Science and Technology of Rapid Solidification and Processing, ed. M.A. Otooni, (Kluwer, Netherlands, 1995) pp. 25

4. K. Rätzke, P.W. Hüppe and F. Faupel, Phys. Rev. Lett. 68, 2347 (1992)

5. H.A. Bruck, T. Chrisman, A.J. Rosakis, and W.L. Johnson, Scripta Metall. 30, 429 (1994)

6. Positron Solid State Physics, ed. W. Brandt and A. Dupasquier (North-Holland, Amsterdam, 1983); Positron Spectroscopy of Solids, ed. A. Dupasquier and A.P. Mills, Jr., (IOS, Amsterdam, 1995)

7. C. Nagel, K. Rätzke, E. Schmidtke, J. Wolff, U. Geyer, and F. Faupel, Phys. Rev. B 57, 10224 (1998).

8. P. Asoka-Kumar, J. Hartley, R. Howell, P.A. Sterne and T.G. Nieh, Appl. Phys. Lett. 77, 1973 (2000).

9. S. Matsui, J. Phys. Soc. Jpn. 61, 187 (1992)

10. M. Alatalo, H. Kauppinen, K. Saarinen, M.J. Puska, J. Mäkinen, P. Hautojärvi, and R.M. Nieminen, Phys. Rev. B 51, 4176 (1995)

11. P. Asoka-Kumar, M. Alatalo, V.J. Ghosh, A.C. Kruseman, B. Nielsen, and K.G. Lynn, Phys. Rev. Lett. 77, 2097 (1996)

12. J.H. Hartley, R.H. Howell, and P.A. Sterne, Applications of Accelerators in Research and Industry, ed. J.L. Duggan and I.L. Morgan (American Institute of Physics, New York, 1999) pp. 366

13. D. Suh and R.H. Dauskardt, Scripta Materiala 42, 233 (2000)

14. D. Suh and R.H. Dauskardt, this symposium 